\title{
Self-Care Activities Among Patients with Diabetes Attending a Tertiary Care Hospital in Mangalore Karnataka, India
}

\author{
Rajasekharan D, Kulkarni V, Unnikrishnan B, Kumar N, Holla R, Thapar R \\ Department of Community Medicine, Kasturba Medical College (Affiliated to Manipal University), Mangalore, \\ Karnataka, India
}

\begin{tabular}{l}
\hline Address for correspondence: \\
Dr. Vaman Kulkarni, \\
Department of Community \\
Medicine, Kasturba Medical College \\
(Affiliated to Manipal University), \\
Mangalore - 575 oo1, Karnataka, India. \\
E-mail: drkulkarni.vaman@gmail.com \\
\hline
\end{tabular}

E-mail: drkulkarni.vaman@gmail.com

\begin{abstract}
Background: Increasing prevalence of diabetes in India is resulting in an epidemiological transition. The care of the people with diabetes is traditionally seen as doctor centered, but the concept of self-care of people with diabetes is a new domain and is proven beneficial. Aim: The aim was to determine the practice of self-care activities among people with diabetes attending a tertiary care hospital in Mangalore. Subjects and Methods: A facility-based cross-sectional study was conducted in Government Wenlock Hospital, Mangalore during September-October 2012. A total of 290 patients with $>1$-year duration of diabetes mellitus (DM) were asked to respond to summary diabetes self-care activities questionnaire after obtaining the consent from them. The statistical analysis was performed in terms of descriptive statistics and association between the variables was tested using Mann-Whitney U-test. Results: A healthy eating plan on a daily basis was followed by $45.9 \%(133 / 290)$ of the participants, daily exercises for $30 \mathrm{~min}$ were followed by $43.4 \%$ (126/290), and regular blood sugar monitoring was done by $76.6 \%$ (222/290). Regarding the adherence to oral hypoglycemic agents and insulin, daily adherence to medication was seen among $60.5 \%(155 / 256)$ and $66.9 \%(138 / 206)$ were found to be adherent to insulin injections on a daily basis. Conclusions: Self-care practices were found to be unsatisfactory in almost all aspects except for blood sugar monitoring and treatment adherence. As these practices are essential for prevention of complications and better quality-of -life, more efforts should be put to educate the people with diabetes.
\end{abstract}

Keywords: Cross-sectional studies, Diabetes mellitus, India, Self-care

\section{Introduction}

The prevalence of diabetes mellitus (DM) has been increasing all over the world in past 30 years, and particularly higher prevalence is seen in the Indian Subcontinent. According to the International Diabetes Federation (IDF), the global diabetes prevalence for the year 2013 was found to be $8.3 \%$, affecting 382 million adults and it is projected to increase to $8.8 \%$ and 592 million adults by 2035. ${ }^{[1]}$ Currently, India is a country with second highest number of people with type $2 \mathrm{DM}$. As per IDF

\begin{tabular}{|l|l|}
\hline \multicolumn{2}{|c|}{ Access this article online } \\
\hline Quick Response Code: & \\
\hline & \\
\hline
\end{tabular}

data for the year 2013, there were 65.1 million people with diabetes in India, which is predicted to rise up to 109 million by the year 2035. ${ }^{[1]}$

The primary goal of any diabetes treatment is better control of blood sugar levels. The treatment options for diabetes tend to be multiple and lifelong. Several studies have documented low levels of adherence to treatment among patients with diabetes. ${ }^{[2-4]}$ Apart from regular medications, there are other beneficial activities that can help in improvement of quality-of-life among patients with diabetes and can lead to better prevention and control of imminent complications such as diabetic nephropathy, diabetic retinopathy and neuropathy through better control of blood sugar levels. Such activities include, healthy eating, being physically active, regular monitoring of blood sugar levels, taking regular medications, good problem-solving skills, healthy coping skills and risk-reduction behaviors. 
The progression of diabetes and its complications are mainly influenced by poor awareness and practices among patients with diabetes.$^{[5]}$ Regular practice of these activities is associated with good outcomes among people with diabetes. ${ }^{[6,7]}$ In developing countries like India, where the resources are limited, and treatment costs for diabetes are constantly increasing, ${ }^{[7-10]}$ the self-care component among patients with diabetes may lead to better economic and therapeutic outcomes.

Currently, there is a dearth of literature regarding self-care practices among people with diabetes in the Indian subcontinent. ${ }^{[11-16]}$ The available literature shows poor compliance of patients with diabetes regarding self-care advices by healthcare providers. Hence, this study would like to add evidence regarding the self-care component in the management of people with diabetes in India by assessing the practice of self-care activities among them.

\section{Subjects and Methods}

\section{Study design and duration}

A facility based cross-sectional study was conducted during the months of September and October, 2012.

\section{Study setting}

The study was conducted at the medical out-patient department (OPD) of Government Wenlock Hospital (GWH), an associate hospital of Kasturba Medical College (KMC), Mangalore. The city of Mangalore is located in the coastal region of Karnataka state. It is the second fastest developing city of Karnataka state, with a highly industrialized work environment. The prevalence of DM in the coastal Karnataka is $16 \%{ }^{[17]}$ The healthcare system in Mangalore is highly privatized with the presence of six private medical colleges and a sea of private clinics. The GWH is a tertiary care level district hospital, which is having a public private partnership (PPP) with KMC, Mangalore. It is one of the oldest PPP model in the country since the year 1955 . The GWH not only caters to the residents of Mangalore city but people from adjoining districts too. The OPD case load for every day ranges from 200 to 300 patients, among whom $60-70$ patients will be with diabetes for follow-up care. Apart from everyday medical OPDs, on every Wednesday diabetes clinic is conducted. The patients with diabetes are, usually, attended by the consultant doctors, junior residents and interns.

\section{Study participants}

The participants of our study included patients with physician-diagnosed type-2 DM, with a duration of illness of minimum 1 year.

\section{Sample size estimation}

A sample size of 264 was calculated considering a power of $80 \%$, confidence level of $95 \%$, an absolute precision of $6 \%$ and assuming the prevalence of self-care activities among patients with diabetes to be $50 \%$. Considering a non-response rate of $10 \%$, the total sample size came out to be 290 subjects.

\section{Sampling}

The participants were selected using convenient sampling.

\section{Study instruments}

The information regarding self-care activities among patients with diabetes was collected using the revised version of summary diabetes self-care activities questionnaire (SDSCA) ${ }^{[18]}$ It is a validated questionnaire used in various settings. ${ }^{[19]}$ The revised SDSCA consists of five components on diet, exercise, blood sugar testing, foot care and smoking. In addition to these items, in expanded version there are few more questions in relation to each of the components along with items on medication practices. Among these components, we included diet, exercise, blood sugar testing, foot care and medication practices. We excluded the smoking component since we have already asked about the smoking history in the socio-demographic section of the questionnaire. Under each section, the participants were asked to respond in past seven days how often they were able to practice the self-care behaviors. Based on their responses, the scoring was done on an ordinal scale of $0-7$. The pattern is uniform for all aspects, except blood sugar testing for which the timeframe is taken for past 3 months. Prior to the onset of the study, the questionnaire was translated into local language (Kannada) and pre-tested among small group of patients with diabetes and necessary modifications were made in terms of comprehensibility and content of the questionnaire.

Apart from the self-care aspects we also collected information in relation to socio-demographic characteristics of the participants such as age, gender, marital status, literacy level, smoking and alcohol consumption, socio-economic status, etc., The socio-economic status of the participants was calculated using Modified Kuppuswamy's scale. ${ }^{[20]}$

\section{Statistical analysis}

Data were entered and analyzed using SPSS version 11.0 (Chicago IL, USA). Descriptive statistics like medians (interquartile ranges) and proportions were used. To understand the effect of duration of diabetes on the self-care practices among the participants, the study population was divided into those with duration of $\mathrm{DM}<10$ years and those with duration of $\mathrm{DM}$ 10 years or more. The cut-off used was arbitrarily selected based on a prior hypothesis that the practice of self-care practices will be better among those with duration of DM 10 years or more considering the prolonged exposure to health education measures provided from their attending physicians. The association between the variables was tested using Mann-Whitney U-test.

\section{Ethical considerations}

Prior to the onset of the study, ethical approval was obtained from Institutional Ethics Committee (IEC) of KMC, Mangalore. A written informed consent was obtained from all 
the study participants. All the collected information was kept confidential, and it is being used for research purpose only.

\section{Results}

Among the 290 patients with diabetes included in the study, $60.0 \%$ (174/290) were males compared to females $40.0 \%$ (116/290). The mean age of the study participants was found to be 47.9 (8.9) years (confidence interval: 46.4-49.5). The socio-demographic details of the study participants are shown in Table 1.

Majority of the participants in our study had duration of DM $<10$ years $70.3 \%$ (204/290). The median duration of DM among the study participants was found to be 6.5 (IQR 3-12.5) years.

Among the study participants, 45.9\% (133/290) had a healthy eating plan for all days of the week [Table 2]. Whereas, $26.2 \%(76 / 290)$ participants consumed fruits/vegetables on all days of the week, 10.7\% (31/290) consumed fried food products on all days of the week and 6.2\% (18/290) participants consumed high fat diet on all days of the week.

\begin{tabular}{|c|c|}
\hline Characteristic & $n(\%)$ \\
\hline \multicolumn{2}{|l|}{ Age (in years) } \\
\hline$<30$ & $023(07.9)$ \\
\hline $31-40$ & $070(24.1)$ \\
\hline $41-50$ & $080(27.7)$ \\
\hline $51-60$ & $054(18.6)$ \\
\hline$>60$ & $063(21.7)$ \\
\hline \multicolumn{2}{|l|}{ Education status } \\
\hline Literates & $232(80.0)$ \\
\hline Illiterates & $058(20.0)$ \\
\hline \multicolumn{2}{|l|}{ Marital status } \\
\hline Married & $246(84.8)$ \\
\hline Unmarried & $044(15.2)$ \\
\hline \multicolumn{2}{|c|}{ Socioeconomic status } \\
\hline Lower & $160(55.2)$ \\
\hline Middle & $065(22.4)$ \\
\hline Upper & $065(22.4)$ \\
\hline \multicolumn{2}{|l|}{ Smoking status } \\
\hline Smokers & $086(29.7)$ \\
\hline Nonsmokers & $204(70.3)$ \\
\hline \multicolumn{2}{|c|}{ Alcohol consumption } \\
\hline Alcoholics & $107(36.9)$ \\
\hline Nonalcoholics & $183(63.1)$ \\
\hline \multicolumn{2}{|l|}{ Health insurance } \\
\hline Yes & $102(35.2)$ \\
\hline No & $188(64.8)$ \\
\hline \multicolumn{2}{|c|}{ Duration since diagnosis of DM } \\
\hline$<10$ years & $204(70.3)$ \\
\hline $10-20$ years & $061(21.1)$ \\
\hline$>20$ years & $025(08.6)$ \\
\hline
\end{tabular}

DM: Diabetes mellitus
Regarding the physical activity component, of the participants $43.4 \%(126 / 290)$ practiced a physical activity of at least $30 \mathrm{~min}$ on all days of the week. A separate exercise session apart from their day to day physical activities was carried out by $17.6 \%(51 / 290)$ participants.

Most of the study participants $64.8 \%$ (188/290) washed their feet daily. Among them 70.7\% (133/290) dried between their toes daily after washing. Very few $28.3 \%$ (82/290) participants checked their feet on all days of the week. Furthermore, very few $13.4 \%$ (39/290) participants examined the inner surface of their shoes for blood or other discharges on all days of the week.

A total of 256 participants were on oral hypoglycemic agents (OHAs), among them adherence to OHAs on all days of the week was practiced by $60.5 \%$ (155/256) of study participants. Among the participants who were on daily insulin injections $(n=206)$, adherence to insulin injections on all days of the week was followed by $66.9 \%$ (138/206) of them. A high proportion of our study participants $76.6 \%(222 / 290)$ underwent blood sugar testing at least once in past 3 months.

Association between self-care practices and duration of DM ( $\geq 10$ years vs. $<10$ years) was performed using Mann-Whitney U-test. There were statistically significant differences between the two groups for the median number of days during which an eating plan was followed (more among those with duration $\geq 10$ years, $P<0.01$ ) and high-fat diet consumption (less if DM duration $\geq 10$ years, $P=0.04$ ).

Table 2: Practice of diabetic self-care components among study participants

\begin{tabular}{lc}
\hline Self-care component & $\boldsymbol{n}(\%)$ \\
\hline $\begin{array}{l}\text { Following a healthy eating plan on all days of } \\
\text { the week ( } n=290)\end{array}$ & $133(45.9)$ \\
$\begin{array}{l}\text { Incorporating fruits/vegetables in the diets on } \\
\text { all days of the week ( } n=290)\end{array}$ & $076(26.2)$ \\
$\begin{array}{l}\text { Consumption of fried food products on all days } \\
\text { of the week ( } n=290)\end{array}$ & $031(10.7)$ \\
$\begin{array}{l}\text { Consumption of high fat diet on all days of the } \\
\text { week ( } n=290)\end{array}$ & $018(06.2)$ \\
$\begin{array}{l}\text { At least } 30 \text { min of physical activity on a daily } \\
\text { basis (e.g., walking, jogging etc.) ( } n=290)\end{array}$ & $126(43.4)$ \\
$\begin{array}{l}\text { Specific exercise session apart from the routine } \\
\text { physical activity on a daily basis ( } n=290)\end{array}$ & $051(17.6)$ \\
$\begin{array}{l}\text { Blood sugar testing at least for once in past 3 } \\
\text { months ( } n=290)\end{array}$ & $222(76.6)$ \\
$\begin{array}{l}\text { Adherence to oral hypoglycemic agents on all } \\
\text { days of the week ( } n=256)\end{array}$ & $155(60.5)$ \\
$\begin{array}{l}\text { Adherence to insulin injections on all days of } \\
\text { the week ( } n=206 \text { ) }\end{array}$ & $138(66.9)$ \\
$\begin{array}{l}\text { Washing feet on all days of the week ( } n=290) \\
\text { Drying in between the toes on all days of the } \\
\text { week ( } n=290)\end{array}$ & $188(64.8)$ \\
$\begin{array}{l}\text { Examining feet on all days of the week ( } n=290) \\
\text { Inspecting the inner surface of shoes on all } \\
\text { days of the week ( } n=290)\end{array}$ & $133(70.7)$ \\
\hline
\end{tabular}


There was no statistically significant difference between the two groups with regards to consumption of fruits/vegetables in their diet and consumption of fried foods [Table 3].

There was no statistically significant difference in relation to practicing daily physical activities among those with duration of DM $<10$ years (Median-6, IQR 3-7) and duration of $\mathrm{DM} \geq 10$ years (Median-6, IQR 4-7, $P=0.50$ ). Similarly, there was no statistically significant difference with regards to practicing a separate physical activity session among those with duration of $\mathrm{DM}<10$ years (Median-6, IQR 3-7) and duration of $\mathrm{DM} \geq 10$ years (Median 6, IQR 4-7, $P=0.30$ ) [Table 3].

Regarding the foot care component, there was a statistically significant difference in relation to drying between the toes after washing of feet, between participants with duration of $\mathrm{DM}<10$ years (Median-5, IQR 1-7) and participants with duration of $\mathrm{DM} \geq 10$ years (Median-7, IQR 1.75-7, $P=0.04$ ). However, there was no statistically significant difference between the two groups in relation to other components of foot care [Table 3].

Adherence to OHAs was found to be similar among the two groups, and the comparison was not statistically significant $(P=0.70)$. Similarly, adherence to insulin injection was found to be of no statistical significance among those with duration of DM $<10$ years (Median-6, IQR 1-7) and duration of $\mathrm{DM} \geq 10$ years (Median-7, IQR 1.75-7, $P=0.10$ ).

\section{Discussion}

The present study was done to assess the practice of diabetes self-care activities among patients attending a tertiary care hospital. The overall practice of dietary component of self-care activity was found to be low among our study participants

\begin{tabular}{|c|c|c|c|c|}
\hline \multirow[t]{2}{*}{ Self-care component } & \multicolumn{2}{|c|}{ Duration of DM (IQR) } & \multirow[t]{2}{*}{$Z$} & \multirow[t]{2}{*}{$P$} \\
\hline & $\begin{array}{l}<10 \text { years } \\
\text { median }\end{array}$ & $\begin{array}{l}\geq 10 \text { years } \\
\text { median }\end{array}$ & & \\
\hline \multicolumn{5}{|l|}{ Diet } \\
\hline Eating plan & $6(4-7)$ & $7(5-7)$ & -2.67 & $<0.01$ \\
\hline Fruits/vegetables in diet & $4(2-7)$ & $4(2-6)$ & -0.07 & 0.94 \\
\hline Fried foods & $4(2-5)$ & $3(1-5)$ & -1.33 & 0.18 \\
\hline High fat diet & $3(2-4)$ & $2(1-4)$ & -2.00 & 0.04 \\
\hline \multicolumn{5}{|l|}{ Physical activity } \\
\hline Daily physical activities & $6(3-7)$ & $6(4-7)$ & -0.59 & 0.55 \\
\hline $\begin{array}{l}\text { Separate exercise } \\
\text { sessions }\end{array}$ & $2(1-5.7)$ & $2(1-5.2)$ & -0.95 & 0.33 \\
\hline \multicolumn{5}{|l|}{ Foot care } \\
\hline Washing feet & $7(5-7)$ & $7(5-7)$ & -0.81 & 0.41 \\
\hline Drying web of toes & $5(1-7)$ & $7(1.7-7)$ & -2.12 & 0.04 \\
\hline Checking feet & $3(1-7)$ & $4(1-7)$ & -0.42 & 0.67 \\
\hline $\begin{array}{l}\text { Inspecting inner surface } \\
\text { of shoes }\end{array}$ & $1(0-3)$ & $1(0-3.2)$ & -0.19 & 0.85 \\
\hline
\end{tabular}

as $<1 / 2(45.9 \%)$ of the participants followed a diet plan regularly. Similar findings were observed by Padma et al. ${ }^{[14]}$ The importance of following a regular dietary plan in terms of both quantity and quality lies in the fact that adequate blood sugar control and proper weight management are linked to it. Also, about one-fourth of our study participants (26.2\%) included vegetables and fruits in their diet on all days of the week. This finding is consistent with a study by Gopichandran et al..$^{[11]}$ The World Health Organization (WHO) recommends a minimum of $400 \mathrm{~g}$ of fruit and vegetables per day ${ }^{[21]}$ Adequate intake of fruits and vegetables not only helps in better control of blood sugar levels but also keeps at bay complications such as cardiovascular diseases, stroke, gastrointestinal tumors, etc. ${ }^{[22]}$ Better awareness in this direction is essential for patients with diabetes and hence more efforts should be made for this component. However, it was encouraging noting that very few participants consumed fried foods (10.7\%) and high-fat diet $(6.2 \%)$ on all days of the week. Similar findings were observed in a study by Gopichandran et al.$^{[1]}$ Consumption of diet rich with fats, especially unhealthy fats such as saturated and trans fats is a major risk factor for cardiovascular events such as arteriosclerosis, myocardial infarction and stroke. ${ }^{[23]}$ The risk of cardiovascular disease is more among people with DM. Hence, it is important to stress upon this aspect of dietary self-care behaviors for all the patients with diabetes.

The physical activity component of self-care activities appeared to be practiced poorly among our study participants, as only $43.4 \%$ of them did a 30 min exercise every day and $17.6 \%$ carried out a separate exercise session apart from daily exercise. Similar findings were observed in studies conducted in India and abroad. ${ }^{[11,24]}$ Regular exercises are recommended for people with diabetes as they have got many beneficial effects like better blood sugar control, reduction in insulin resistance, better control of blood pressure levels and cardioprotective action. ${ }^{[25]}$ More stress should be placed on the physical activity component of diabetes self-care education.

More than three-fourth of our study participants checked blood sugar levels at least once in 3 months. Similar findings were observed in studies conducted elsewhere. ${ }^{[11,26,27]}$ Regular monitoring of blood sugar levels is vital in the management of diabetes, as it helps in assessing the effectiveness of the ongoing treatment regimen of the patient. Blood glucose monitoring at home is not prevalent in the study area, and thus assessment of practice of home blood glucose level monitoring was not done in our study. Adherence to oral hypoglycemic drugs $(60.5 \%)$ and insulin injections $(66.9 \%)$ was found to be high among our study participants. The adherence rates to pharmacotherapy in our study are less compared with the study conducted by Gopichandran et al. ${ }^{[11]}$ in which an adherence rate of $79 \%$ was identified. The above mentioned study was conducted in a community, which is closely monitored by a Community Health Department of a medical college; hence the participants are likely to be more aware about the importance of adherence to pharmacotherapy of diabetes due to provision 
of repeated health education measures and constant monitoring of the study population. In contrast, our study participants were people visiting to OPDs of tertiary care hospitals for follow-up from different areas of the city and surroundings. Nonetheless, this finding highlights the importance of health education for better control of diabetes in a developing country like India.

The practice of washing of feet every day and drying between the toes $(70.7 \%)$ were found in the majority of our study participants $(64.8 \%)$. This finding is in contrast to a study conducted by Nadia Saeed in Pakistan ${ }^{[28]}$ in which only $20 \%$ of the participants practiced washing feet on a daily basis and $23 \%$ dried them properly. This difference may be due to the practice of frequent washing of feet in India due to religious and cultural reasons. However, the practice of other important aspects of foot care, such as daily feet examination (28.3\%) and inspection of inner surface of shoes for any discharge (13.4\%) were found to be low among our study participants. Similar findings were observed in studies conducted elsewhere. ${ }^{[28,29]}$ The practice of foot care components is essential for the prevention of foot ulcers and subsequent development of a gangrenous lesion that can lead to limb amputations thus resulting in increased disability and handicap. The fact of poor adherence to medications coupled with poor foot care puts additional risk for the study population. Hence, awareness generation in this regard is essential.

The statistical comparison between the group with $<10$ years DM duration and more than 10 years DM yielded better practices among participants with more than 10 years DM in few aspects such as having a diet plan, consumption of high fat diet and drying between the webs of toes. This might be explained by the fact that accumulated experience of various aspects of DM care coupled with frequent exposure to self-care education measures might be responsible for this finding.

The strength of our study is that we reported multiple aspects of self-care among patients with diabetes using a valid scale. Limitations mainly include the study setting itself, as our study is a facility-based study hence generalization of our findings to other settings may not be possible. All the self-care practices in our study were self-reported. Furthermore, the responses to some questions, especially diet related seem over simplified hence they should be read with caution and in the future might be dealt with more detailed techniques like $24 \mathrm{~h}$ dietary recall.

\section{Conclusion}

The practice of self-care practices was found to be unsatisfactory in almost all aspects except for blood sugar monitoring and adherence to treatment. As these practices are essential for prevention of the multitude of complications and better quality of life, more efforts should be put to educate the patients through existing facilities in both government and private healthcare facilities. Future research regarding self-care practices should be conducted with the help of community-based studies to increase the external validity.

\section{Acknowledgment}

The authors are grateful to the study participants' who voluntarily participated in the study. We wish to acknowledge Manipal University for encouraging research and its publication in international journals of repute.

\section{References}

1. International Diabetes Federation. IDF Diabetes Atlas. $6^{\text {th }}$ ed. Brussels, Belgium: International Diabetes Federation; 2013. Available from: http://www.idf.org/diabetesatlas. [Last accessed on 2014 Mar 01].

2. Shobana R, Augustine C, Ramachandran A, Vijay V. Improving psychosocial care: The Indian experience. Diabetes Voice 2005;50:19-21.

3. Chew LD. The impact of low health literacy on diabetes outcomes. Diabetes Voice 2004;49:30-2.

4. Kalyango JN, Owino E, Nambuya AP. Non-adherence to diabetes treatment at Mulago Hospital in Uganda: Prevalence and associated factors. Afr Health Sci 2008;8:67-73.

5. Ramachandran A, Snehalatha C, Baskar AD, Mary S, Kumar CK, Selvam S, et al. Temporal changes in prevalence of diabetes and impaired glucose tolerance associated with lifestyle transition occurring in the rural population in India. Diabetologia 2004;47:860-5.

6. AADE. AADE7 Self-Care Behaviors. Diabetes Educ 2008;34:445-9.

7. Shobhana R, Begum R, Snehalatha C, Vijay V, Ramachandran A. Patients' adherence to diabetes treatment. J Assoc Physicians India 1999;47:1173-5.

8. Kapur A. Economic analysis of diabetes care. Indian J Med Res 2007;125:473-82.

9. Loganathan AC, John KR. Economic burden of diabetes in people living with the disease; a field study. J Diabetol 2013;3:4.

10. Rayappa PH, Raju KN, Kapur A, Bjork S, Sylvest C, Kumar KM. Economic cost of diabetes care the Bangalore Urban District Diabetes Study. Int J Diabetes Dev Ctries 1999;19:87-97.

11. Gopichandran V, Lyndon S, Angel MK, Manayalil BP, Blessy KR, Alex RG, et al. Diabetes self-care activities: A community-based survey in urban southern India. Natl Med J India 2012;25:14-7.

12. Priya D, Hiwarkar PA, Khakse GM, Wahab SN. Self-health care practices among type 2 diabetes patients attending diabetes clinic in India: A descriptive cross-sectional study. Int J Recent Trends Sci Technol 2012;4:116-9.

13. Kaur K, Singh MM, Kumar, Walia I. Knowledge and self-care practices of diabetics in a resettlement colony of Chandigarh. Indian J Med Sci 1998;52:341-7.

14. Padma K, Bele DS, Bodhare TN, Valsangkar S. Evaluation of knowledge and self-care practices in diabetic patients and their role in disease management. Natl J Community Med 2012;3:3-6.

15. Raithatha SJ, Shankar SU, Dinesh K. Self-Care Practices among Diabetic Patients in Anand District of Gujarat. ISRN Family Med 2014;2014:743791. 
16. Surendranath A, Nagaraju B, Padmavathi GV, Anand SC, Fayaz P, Balachandra G. A study to assess the knowledge and practice of insulin self-administration among patients with diabetes mellitus. Asian J Pharm Clin Res 2012;5:63-6.

17. Rao CR, Kamath VG, Shetty A, Kamath A. A study on the prevalence of type 2 diabetes in coastal Karnataka. Int J Diabetes Dev Ctries 2010;30:80-5.

18. Toobert DJ, Hampson SE, Glasgow RE. The summary of diabetes self-care activities measure: Results from 7 studies and a revised scale. Diabetes Care 2000;23:943-50.

19. Jalaludin MY, Fuziah MZ, Hong JY, Mohamad Adam B, Jamaiyah $\mathrm{H}$. Reliability and validity of the revised summary of diabetes self-care activities (SDSCA) for Malaysian children and adolescents. Malays Fam Physician 2012;7:10-20.

20. Kumar N, Shekhar C, Kumar P, Kundu AS. Kuppuswamy's socioeconomic status scale-updating for 2007. Indian J Pediatr 2007;74:1131-2.

21. Fruit and Vegetables for Health, Kobe, Japan: Report of a Joint FAO/WHO Workshop; 1-3 September, 2004. Available from: http://www.who.int/dietphysicalactivity/publications/ fruit_vegetables_report.pdf. [Last accessed on 2013 Nov 15].

22. Lock K, Pomerleau J, Causer L, Altmann DR, McKee M. The global burden of disease attributable to low consumption of fruit and vegetables: Implications for the global strategy on diet. Bull World Health Organ 2005;83:100-8.

23. Willett WC. Dietary fats and coronary heart disease. J Intern Med 2012;272:13-24.
24. Hailu E, Wudineh HM, Belachew T, Birhanu Z. Self-care practice and glycaemic control amongst adults with diabetes at the Jimma University Specialized Hospital in south-west Ethiopia: A cross-sectional study. Afr J Prim Health Care Fam Med 2012;4:34-9.

25. Cayley WE. The role of exercise in patients with type 2 diabetes. Am Fam Physician 2007;75:335-6.

26. Ayele K, Tesfa B, Abebe L, Tilahun T, Girma E. Self care behavior among patients with diabetes in Harari, Eastern Ethiopia: The health belief model perspective. PLoS One 2012;7:e35515.

27. Guo XH, Yuan L, Lou QQ, Shen L, Sun ZL, Zhao F, et al. A nationwide survey of diabetes education, self-management and glycemic control in patients with type 2 diabetes in China. Chin Med J (Engl) 2012;125:4175-80.

28. Saeed N, Zafar J, Atta A. Frequency of patients with diabetes taking proper foot care according to international guidelines and its impact on their foot health. J Pak Med Assoc 2010;60:732-5.

29. Jinadasa CV, Jeewantha M. A study to determine the knowledge and practice of foot care in patients with chronic diabetic ulcer. Int J Collab Res Intern Med Public Health 2011;3:115-22.

How to cite this article: Rajasekharan D, Kulkarni V, Unnikrishnan B, Kumar N, Holla R, Thapar R. Self-care activities among patients with diabetes attending a tertiary care hospital in Mangalore Karnataka, India. Ann Med Health Sci Res 2015;5:59-64.

Source of Support: Nil. Conflict of Interest: None declared. 